\title{
Analysis of the accuracy of Shuttle Radar Topography Mission (SRTM) height models using International Global Navigation Satellite System Service (IGS) Network
}

\author{
Manas Mukul ${ }^{1}$, Vinee Srivastava ${ }^{2}$ and Malay Mukul ${ }^{2, *}$ \\ ${ }^{1}$ Kalinga Institute of Industrial Technology, Bhubaneswar 751 024, India. \\ ${ }^{2}$ Continental Deformation Laboratory, Department of Earth Sciences, Indian Institute of Technology Bombay, \\ Mumbai 400 076, India. \\ *Corresponding author.e-mail: malaymukul@iitb.ac.in
}

The Shuttle Radar Topography Mission (SRTM) carried out in February 2000 has provided near global topographic data that has been widely used in many fields of earth sciences. The mission goal of an absolute vertical accuracy within $16 \mathrm{~m}$ (with 90\% confidence)/RMSE $\sim 10 \mathrm{~m}$ was achieved based on ground validation of SRTM data through various studies using global positioning system (GPS). We present a new and independent assessment of the vertical accuracy of both the X- and C-band SRTM datasets using data from the International GNSS Service (IGS) network of high-precision static GPS stations. These stations exist worldwide, have better spatial distribution than previous studies, have a vertical accuracy of $6 \mathrm{~mm}$ and constitute the most accurate ground control points (GCPs) possible on earth; these stations are used as fiducial stations to define the International Terrestrial Reference Frame (ITRF). Globally, for outlier-filtered data (135 X-band stations and 290 C-band stations), the error or difference between IGS and SRTM heights exhibits a non-normal distribution with a mean and standard error of $8.2 \pm 0.7$ and $6.9 \pm 0.5 \mathrm{~m}$ for $\mathrm{X}$ - and C-band data, respectively. Continent-wise, Africa, Australia and North America comply with the SRTM mission absolute vertical accuracy of $16 \mathrm{~m}$ (with 90\% confidence)/RMSE 10 m. However, Asia, Europe and South America have vertical errors higher than the SRTM mission goal. At stations where both the X- and C-band SRTM data were present, the root mean square error (RMSE) of both the $\mathrm{X}$ - and C-bands was identical at $11.5 \mathrm{~m}$, indicating similar quality of both the X- and C-band SRTM data.

\section{Introduction}

The Shuttle Radar Topography Mission (SRTM) was a joint project carried out by the US National Imagery and Mapping Agency (NIMA) (now known as National Geospatial Intelligence Agency (NGA)), the US National Aeronautics and Space Administration (NASA), the German Aerospace Center (DLR) and the Italian Space Agency (ASI) for three-dimensional digital mapping of the globe (Van Zyl 2001). The main objective of the SRTM project was to collect near-global topographic data with absolute horizontal and vertical accuracies better than 20 and $16 \mathrm{~m}$, respectively, with $90 \%$ confidence (Rabus et al. 2004; USGS 2005; Farr et al. 2007, JPL 2009); this $16 \mathrm{~m}$ linear error at $90 \%$ confidence (LE90) corresponded to a root mean square error (RMSE) of $\sim 10 \mathrm{~m}$, assuming a normal

Keywords. Geodesy; error; accuracy; georeferencing; GPS/GNSS; radar; DEM/DTM; SRTM.

Supplementary data pertaining to this article are available on the Journal of Earth System Science Website at http://www.ias.ac.in/jess/aug2015/supp/Mukul.pdf 
distribution of errors (FGDC 1998; Gesch 2007). The SRTM error could also be divided into verylong-wavelength large errors and short-wavelength random errors (Rodriguez et al. 2005). However, we have considered the absolute vertical error in our study as we could not differentiate the large continental scale errors from the random errors. The SRTM data were released in the year 2000 and since then, these data have been used extensively in a variety of studies in many disciplines of earth sciences such as topographic studies (Falorni et al. 2005), geomorphometric analysis (Sleszynski 2013), vegetation cover studies (Kellndorfer et al. 2004), assessment of tsunami (Blumberg et al. 2005), modelling of soil particle size distribution (Ciampalini et al. 2013) and measuring surface elevation changes of glaciers (Jaber et al. 2013). Given the widespread use of the SRTM data, an assessment of its accuracy is important, and we explored that using a global dataset to complement previous studies where GCPs are not distributed as evenly as in the present study.

\subsection{Shuttle Radar Topography Mission data}

The Shuttle Radar Topography Mission (SRTM) data were collected with a sophisticated synthetic aperture radar (SAR) system with a pair of C- and $\mathrm{X}$-band antennas having carrier frequency 5.3 and $9.6 \mathrm{GHz}$, respectively, and obtained topographic elevation data at $30 \mathrm{~m}$ resolution (Farr and Kobrick 2000) during an 11-day mission (Werner 2001; Rabus et al. 2004) in February 2000. Data were only collected between $60^{\circ} \mathrm{N}$ and $57^{\circ} \mathrm{S}$ latitude (Rabus et al. 2004) as high-latitude regions above $60^{\circ}$ latitude in both the hemispheres were not within the scope of the mission and resulted in the exclusion of about $20 \%$ of the Earth's surface. In addition, regions with heavy vegetation canopy, calm water bodies and heavy radar shadows failed to produce elevation data due to the limitations of the radar and produced data 'voids'. These voids in the SRTM data were corrected either through interpolation or by filling with data from other sources (Grohman et al. 2006; Hoffmann and Walter 2006). This void-filled, finished SRTM C-band data accounted for $80 \%$ of the Earth's surface and is available as a free download in $90 \mathrm{~m}$ spatial resolution. The X-band is available in $30 \mathrm{~m}$ resolution. However, it has a spatial coverage almost half of that of C-band due to its smaller swath width of $45 \mathrm{~km}$ as compared with the $225 \mathrm{~km}$ swath width of C-band (Bamler 1999). The horizontal datum for both C- and X-band SRTM data is the World Geodetic System 1984 (WGS84) ellipsoid. However, the vertical datum is different for the two bands, viz., the Earth Gravity Model (EGM96) geoid for the C-band data and WGS84 ellipsoid for the Xband data (Bamler 1999; Miliaresis and Paraschou
2005). The $90 \mathrm{~m}$ SRTM (C-band) data is available in various versions (V1, V2, V3 and V4) and the version 4.1 SRTM data obtained from the Consultative Group for International Agriculture Research Consortium for Spatial Information (CGIAR-CSI) website (http://srtm.csi.cgiar.org) is the most recent version (Mouratidis et al. 2010). The $30 \mathrm{~m}$ global SRTM data (X-band) has also been released in beta stage and is available as a free download from the DLR website (https://centaurus.caf. dlr.de:8443/eoweb-ng/template/default/welcome/ entryPage.vm). In this study, we have used the C-band version 4.1 SRTM data and X-band DLR SRTM data. The $30 \mathrm{~m}$ X-band Digital Elevation Model (DEM) has a higher accuracy than the 90 m DEM, C-band data (Rabus et al. 2004).

The SRTM mission goal of LE90 error of $16 \mathrm{~m}$ (RMSE $\sim 10 \mathrm{~m}$ ) was assessed worldwide and validated using ground control points (GCPs) measured using dual-frequency, Real Time Kinematic (RTK) GPS (Rodriguez et al. 2005, 2006) for C-band data. As the SRTM data were globally available, many studies have subsequently been carried out to assess the accuracy of the SRTM data using different types of GPS deployed in different ways. The GPS consists of single- or dual-frequency receivers deployed in the static or kinematic mode. In the static mode, a stationary receiver is deployed at the GCP and its position computed. In the kinematic mode, a base receiver is fixed on a known location and the other receiver, known as the rover, can be moved over multiple unknown points with both tracking the same satellites. The rover locations are determined using the difference in known and computed positions of the base station as the error to correct location of unknown positions (El-Rabbany 2002).

Falorni et al. (2005) measured the accuracy (RMSE $8.94 \mathrm{~m}$ ) of the SRTM data used at the Little Washita River basin site, Oklahoma, USA. The C-band SRTM data from regions in Poland (Karwel and Ewiak 2008), Thailand and the US (Gorokhovich and Voustianiouk 2006), Greece (Mouratidis et al. 2010) and India (Agrawal et al. 2006) have been assessed using GPS, and all the results seem to indicate that the SRTM mission goal of $16 \mathrm{~m}$ with $90 \%$ confidence has been adhered to irrespective of the GPS methodology used. This is intriguing and needs to be investigated more carefully and systematically as assessment of the accuracy of the SRTM data is expected to depend on the methodology used. The accuracy of the GPS data used to assess SRTM data should directly impact the result. Hence, it is important to understand the level of accuracy of the GPS data used to validate the SRTM data and work out an optimal way of using the data.

\subsection{Accuracy of GPS data}

As the highest accuracy (millimetre level) is obtained using dual frequency receivers in a static mode with 
post-processing, it is best to use this methodology to compute point locations of GCPs for estimation of SRTM errors (e.g., Agrawal et al. 2006). Postprocessing involves conversion of raw data files obtained from the receivers into receiver independent format and subjecting the converted files to quality checks using the TEQC (translation, editing and quality check) software. They are further refined to filter errors due to atmosphere, satellite, receiver, multipath, etc. Precisely located points are then obtained by constraining them to their ITRF positions (Altamimi et al. 2007). When such points are unavailable, dual-frequency RTK-computed positions for GCPs is the next best option. In fact, the validation for the C-band SRTM errors has been first done by using dual-frequency RTK (Rodriguez et al. 2005, 2006). However, there is an opportunity to further explore and independently test the SRTM errors using post-processed, dual-frequency, static data from an already existing global network of highly precise static GPS stations. All the above-mentioned studies (Agrawal et al. 2006; Gorokhovich and Voustianiouk 2006; Mouratidis et al. 2010) used the kinematic deployment mode. We built on these studies by using a global dataset available in the form of the International GNSS Service network of (IGS) stations.
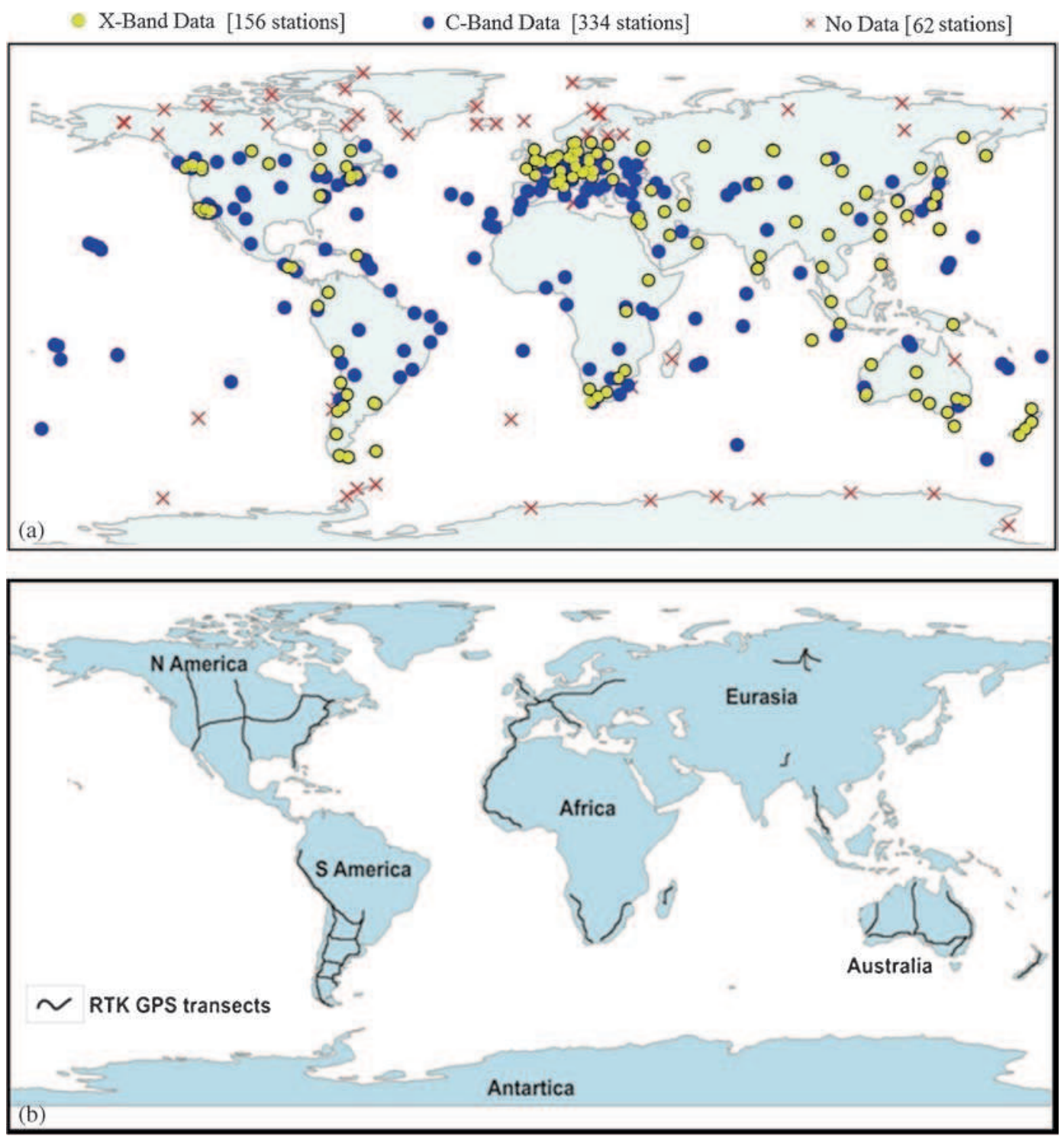

Figure 1. (a) Map showing all the IGS stations with X- and C-band SRTM data. The stations that are not in the SRTM range or do not have any SRTM data are denoted by a red cross. SRTM data were available from 335 IGS stations out of a total of 427 IGS stations. Out of the 335 IGS stations, 155 stations have both C- and X-band data (denoted by the overlapping yellow points over blue). There are 334 stations with C-band and 156 stations with X-band SRTM data. One station has X-band data but no C-band data. (b) Map showing RTK GPS transects used to validate SRTM data worldwide by Rodriguez et al. (2006). 


\subsection{The International GNSS Service network of stations}

The International GNSS Service (IGS) consists of a global network of satellite tracking stations that deploy dual-frequency GPS receivers in static mode to provide high quality post-processed point locations spread throughout the globe (figure 1a). The elevation data provided by the IGS stations have a standard error of 1-6 mm (Dow et al. 2009) and are used as fiducial stations to define the ITRF for studying continental deformation using Geodetic GPS. There are 427 such IGS stations spread throughout the Globe for which the SRTM elevation data is available (figure 1a). Stations having no data for 60 or more days are categorized as dormant sites (http://igscb.jpl.nasa.gov/network/list.html). The highly accurate point locations of these fiducial stations are the best possible locations of GCPs on earth. Therefore, these points can be used as Global GCPs whose elevations can be used to assess the quality of SRTM heights. We, therefore, for the first time use the IGS network data to assess the quality of the SRTM product by comparing elevation data from the SRTM dataset with the high-quality elevation data available at the IGS stations.

The primary objective of this study is, therefore, to evaluate the quality of both X- and C-band SRTM data using high quality IGS GCPs spread globally. This provides an independent way of assessing both $\mathrm{X}$ - and C-band data accuracy at a global level and is intended to complement all the other studies that have been carried out to assess the quality of the SRTM data. We also compare the results of this study with the global accuracy analysis of C-band SRTM data carried out using dual frequency RTK receivers (Rodriguez et al. 2005) with limited, non-uniform transects (figure 1b). Our study has a limitation on the number of GCPs. However, the GCPs have a better spatial distribution (figure 1). Therefore, it would be appropriate to compare the results of the Rodriguez et al. (2005) (figure 1b) having extensive GCPs to that of our study having better spread of the GCPs (figure 1a).

\section{Methodology}

\subsection{Obtaining IGS high-precision static post-processed GPS data}

The IGS location (horizontal and vertical) for all the stations were retrieved from the log files of each station available on the IGS website (http:// igscb.jpl.nasa.gov/network/list.html). The data were further refined to remove the redundant locations with the same latitude and longitude values and also those with latitude greater than $60^{\circ} \mathrm{N}$ and
Table 1. Details of the number of $X$ - and C-band SRTM data available at IGS stations.

\begin{tabular}{lr}
\hline Total IGS stations & 427 \\
Stations with redundant location & 30 \\
Stations out of SRTM range & 44 \\
Stations without X- or C-band SRTM data & 18 \\
Stations with either X- or C-band data & 335 \\
Stations with coincident X- and C-band data & 155 \\
Stations with X-band data & 156 \\
Stations with C-band data & 334 \\
\hline
\end{tabular}

$57^{\circ} \mathrm{S}$ as SRTM values were not available for them. There were 18 additional locations within latitude $60^{\circ} \mathrm{N}$ and $57^{\circ} \mathrm{S}$ whose SRTM values were not available as they were located near- or off-shore. In all, there were 62 stations for which SRTM value was not available (figure 1a).

The final list consisted of 335 IGS stations (Supplementary data; figure 1a) for which either C- or X-band SRTM data were available. 156 stations had X-band data and 334 stations had C-band data. The number of stations having both $\mathrm{X}$ - and Cband data were 155 (table 1). The IGS elevation of the locations varied between -92 (Station \#193) and 3755 m (Station \#215) (Supplementary data; figure 2). From the final list, we selected random IGS points and found their elevation at epoch February 2000 constrained to ITRF2008 positions (http://itrf.ensg.ign.fr/site_info_and_select/solutions_ extraction.php). We compared this elevation to the elevation obtained from the $\log$ files. The difference between the two sets of elevations was in the order of centimetres (absolute mean of the differences were $\sim 6 \mathrm{~cm}$ ). Hence, we have used IGS station elevations from the log files (http://igscb. jpl.nasa.gov/network/list.html) as centimetre-level corrections were considered to be insignificant.

\subsection{Obtaining SRTM C-band data}

The 4.1 version SRTM C-band digital elevation model (DEM) in $90 \mathrm{~m}$ resolution was downloaded from the CGAIR website using the Google Earth Interface. A zipped Keyhole Markup Language (KML) file was available from the CGAIR website. This file contained the tile boundary, tile name and the corresponding download link. A separate KML file for all the IGS data points was created using ArcGIS 10.1 and both the files were superimposed on the map using the Google Earth 7.1 interface. All the tiles that contained the IGS data points were downloaded using the direct download link as a GeoTIFF raster file; GeoTIFF is a standard image file format for GIS applications (Mahammad and Ramakrishnan 2010). The downloaded raster files were imported into ArcGIS as a layer. The IGS points were 


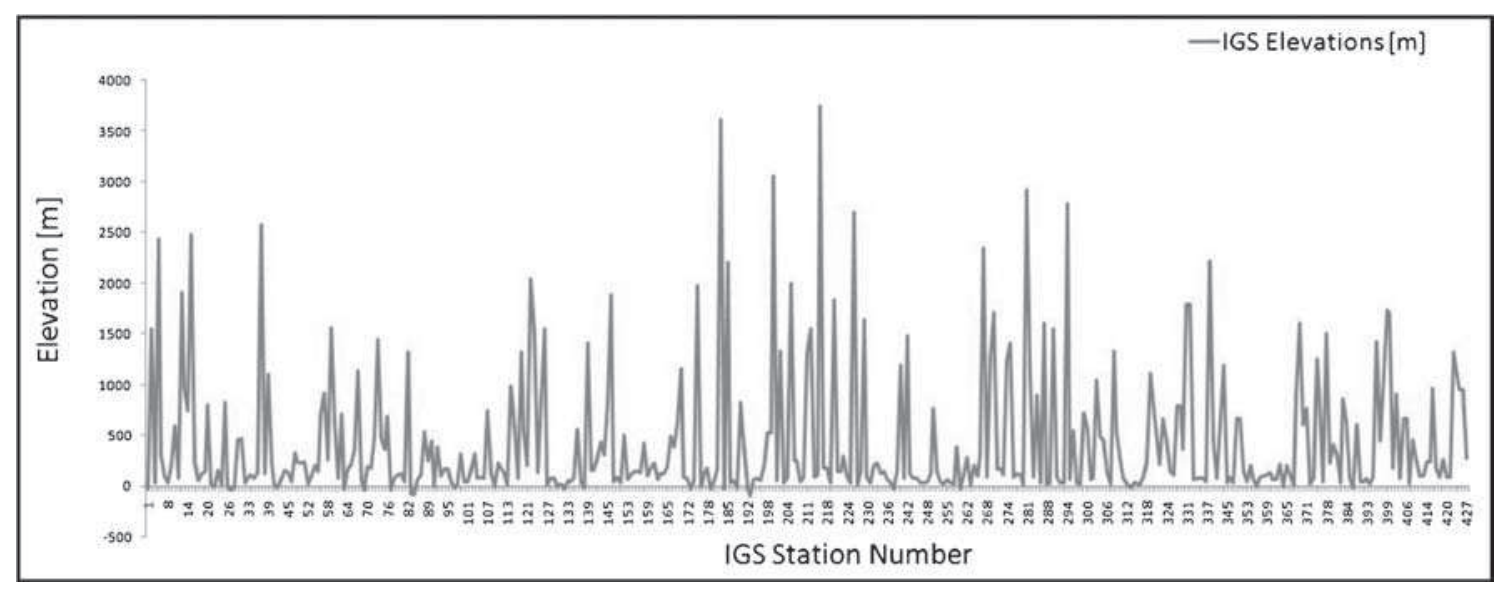

Figure 2. Plot showing the variation of IGS elevation with station code (the data are tabulated in Supplementary data).

superimposed over the SRTM raster file and their corresponding SRTM C-band elevation values were extracted using the spatial analyst tool in ArcGIS 10.1. The downloaded elevations were available as a 16-bit integer values. Since the vertical datum for C-band DEM is the EGM96 geoid (Farr et al. 2007), the extracted elevation values were orthometric heights. The IGS uses a reference frame based on ITRF; ITRF and WGS1984 are within millimetre of each other (http://www. spatial-ed.com/datums/datums-basics/529-wgs84itrf08-igs08-convert.pdf). In order to compare the two elevations, the SRTM heights were converted to the ellipsoidal heights by adding the geoidal height to the elevation for each location. The geoidal heights were found for all the locations using the University NAVSTAR Consortium (UNAVCO) Online Geoid Height Calculator (http://www.unavco.org/ community_science/sciencesupport/geoid/geoid. html) which uses the potential coefficient model EGM96 (Rapp 1997). The error for EGM96 geoidal undulation is in the range \pm 0.5 to $\pm 1.0 \mathrm{~m}$ (Lemoine et al. 1998) worldwide. Therefore, it can be used with SRTM data where a vertical accuracy of $\sim 16 \mathrm{~m}$ was the mission goal. The C-band SRTM data was available for 334 stations (table 1).

\subsection{Obtaining SRTM X-band data}

The SRTM X-band DEM in $30 \mathrm{~m}$ resolution was downloaded from the DLR server through the FTP link (ftp://taurus2.caf.dlr.de/), which is available on registration (https://centaurus.caf.dlr.de:8443/ eoweb-ng/template/default/welcome/entryPage. vm). First, the KML files for all the tiles were downloaded through FTP. All the files were combined and superimposed with the KML file for the IGS stations. The names of the tiles containing the IGS points were found and downloaded through
FTP as a compressed (.zip) file. Each compressed file consists of many smaller sub-tiles. The name of the sub-tiles were found for each station using the 'Earth Observation on the WEB' (EOWEB) interface by entering the latitude and longitude of all the IGS stations. All the sub-tiles were available as a raster file and processed using ArcGIS 10.1 to get the X-band elevation of the corresponding IGS stations. As the X-band DEM used WGS1984 vertical datum (Farr et al. 2007), no height conversion was required, and ellipsoidal heights were directly downloaded. The X-band SRTM data were available for 156 IGS stations (table 1; Supplementary data). The summary of the methodology used is shown in figure 3 .

\subsection{Statistical analysis}

The difference between the GPS ellipsoidal heights and the SRTM (C-band and X-band) ellipsoidal heights was defined as the 'error'. It is difficult to pin-point the reason for this error as it is a manifestation of many interferometric errors like baseline roll errors, phase errors, timing and position errors and beam differential errors. Some of the GPS receivers were placed on elevated structures and rooftops of buildings and these could also add to the error. The C-band, X-band and IGS station elevation datasets were subjected to statistical analysis involving computation of the mean error, mean absolute error, RMS error, standard deviation and standard error of the difference between GPS and SRTM heights (errors) to test the accuracy of the SRTM C- and X-band data at each IGS station. The stations were further segregated into continents and analysed to compare the results with the Rodriguez et al. (2005, 2006) assessment. A stem-and-leaf analysis was performed (figure 4) with the $\mathrm{C}$ - and $\mathrm{X}$-band data to identify the 
high-error points as outliers. These outliers were filtered out from the datasets and analysed. There were $21 \mathrm{X}$-band and $44 \mathrm{C}$-band outliers (figure 4; figure 5a; table 2). The maximum error in the X-band and C-band recorded was 2309.78 and $3687.01 \mathrm{~m}$, respectively (figure $5 \mathrm{~b}$ ). The statistical analysis was, therefore, carried out with $135 \mathrm{X}$-band and 290 C-band data after elimination of the outliers.
Stations with both X- and C-band data were also analysed separately as they give a true comparison of the X-and C-band data. Out of 155 coincident $\mathrm{C}$ - and X-band points, $24 \mathrm{C}$-band and $21 \mathrm{X}$-band points were filtered as outliers (table 3 ).

Analysis with the outlier points showed that the magnitude of the error increased with the increase in IGS station elevation (Hanssen 2001; Toutin

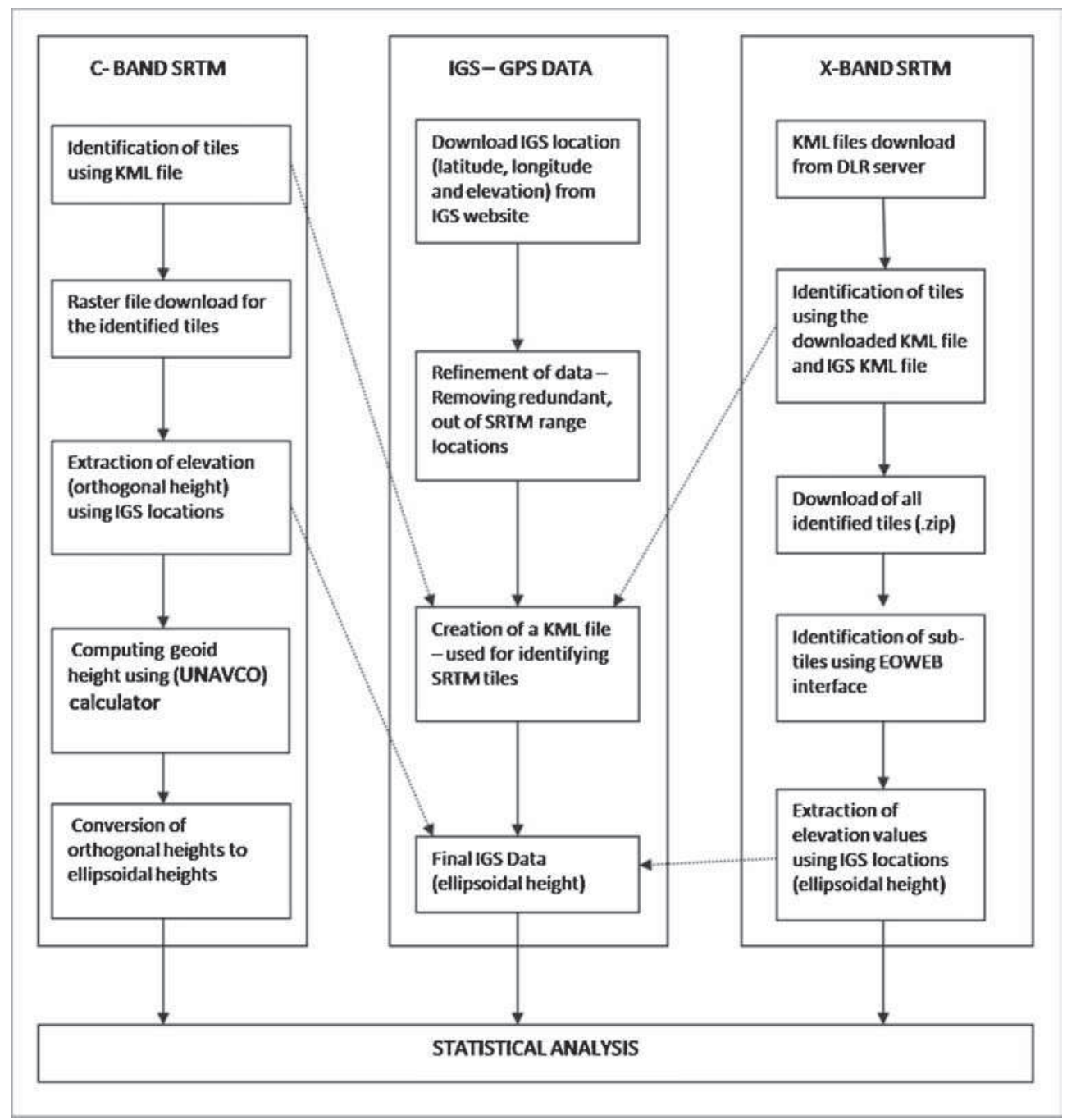

Figure 3. Diagram for the methodology showing the process of data extraction and compilation used in this study.
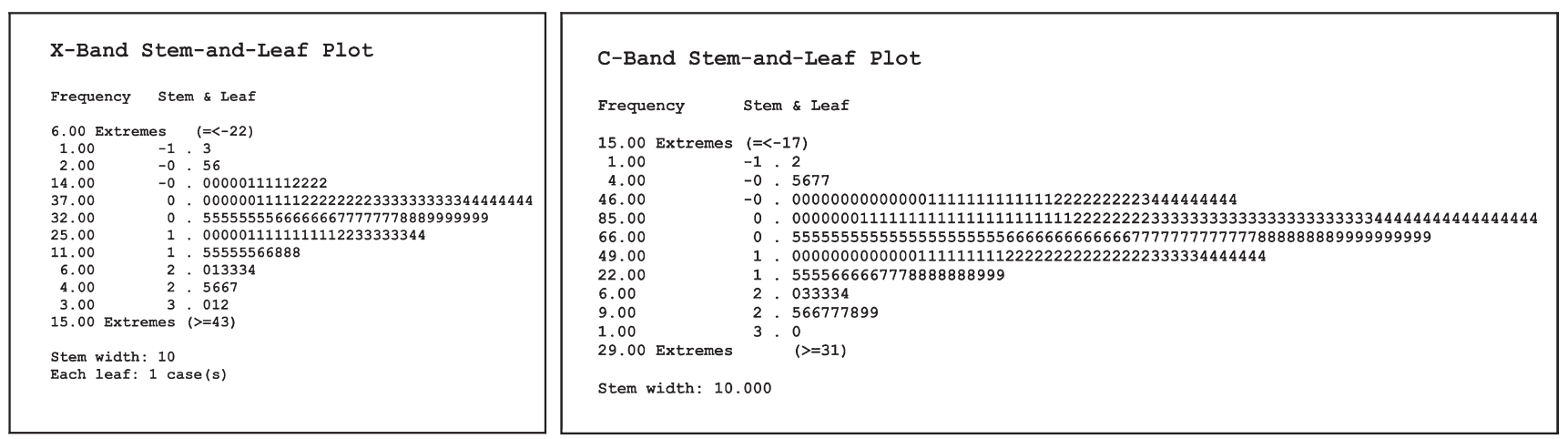

Figure 4. Stem-and-leaf plot showing the presence of 21 outliers for X-band and 44 outliers for C-band data. 

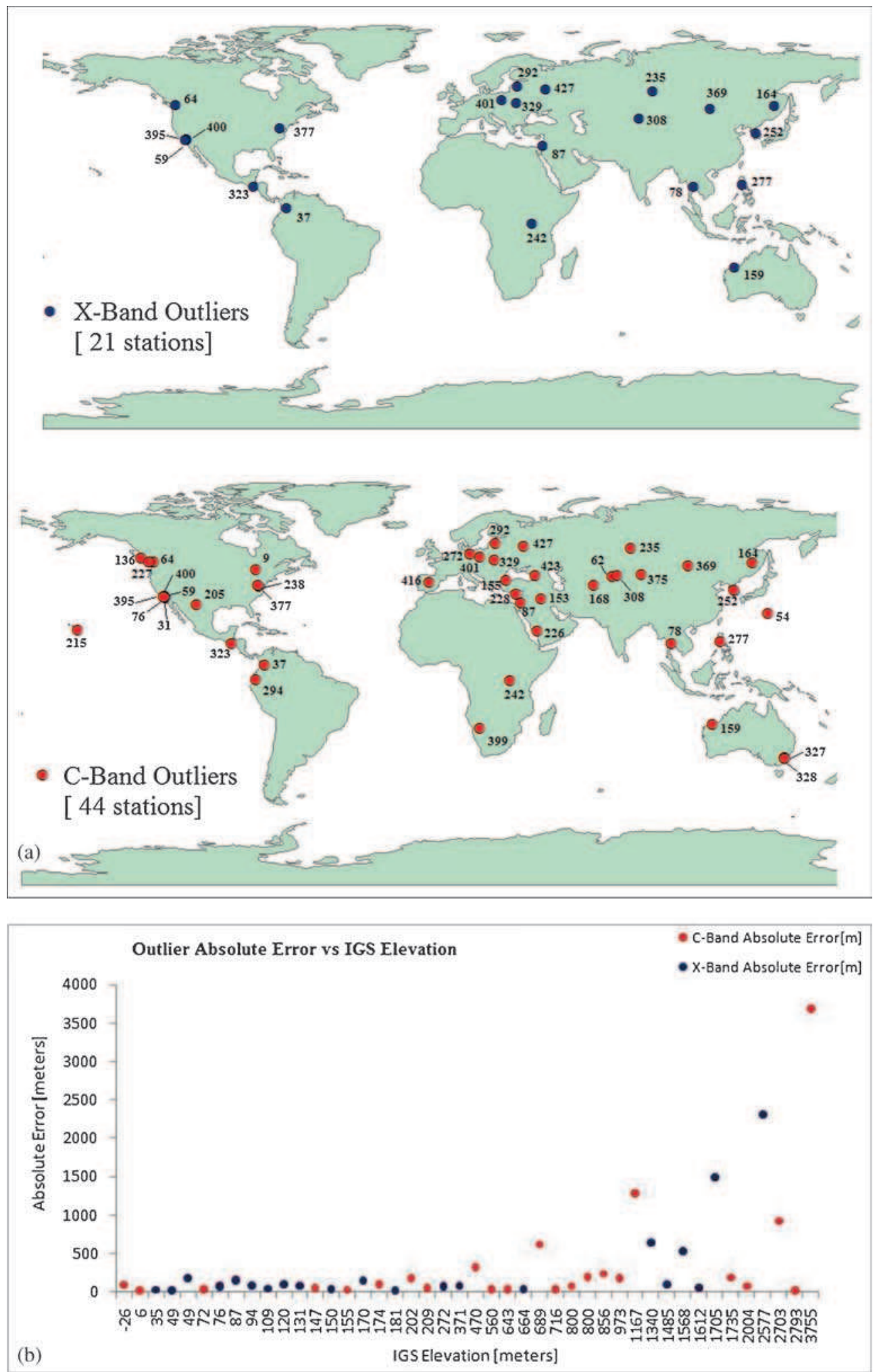

Figure 5. (a) Map showing all the outliers for X-and C-band data. The numbers correspond to the IGS station code of Cand X-band data respectively (Supplementary data). (b) Plot of X- and C-band absolute error magnitude with increasing IGS elevation for the outliers. All X-band (21) outliers are also C-band outliers.

2002). Absolute error was computed for each of the $\mathrm{X}$ - and C-band outlier points and compared with the IGS elevations (figure 5b). This is consistent with the results of other studies (Agrawal et al. 2006;
Gorokhovich and Voustianiouk 2006; Karwel and Ewiak 2008) that showed a decrease in the accuracy of the SRTM data at higher elevations. The elevation value of a single pixel in the SRTM DEM 
Table 2. Results of the statistical analysis of worldwide X-and C-band SRTM data.

\begin{tabular}{|c|c|c|c|c|}
\hline \multirow[b]{3}{*}{ Datasets } & \multicolumn{4}{|c|}{ All IGS stations } \\
\hline & \multicolumn{2}{|c|}{ Without outlier } & \multicolumn{2}{|c|}{ Including outlier } \\
\hline & X-band & C-band & X-band & C-band \\
\hline Total stations considered & 135 & 290 & 156 & 334 \\
\hline Mean error $(\mathrm{m})$ & 8.2 & 6.9 & 34.2 & 32.0 \\
\hline Mean absolute error $(\mathrm{m})$ & 8.8 & 7.8 & 48.4 & 51.0 \\
\hline RMS error (m) & 11.5 & 10.3 & 232.6 & 274.5 \\
\hline Standard deviation $(\mathrm{m})$ & 8.1 & 7.8 & 230.8 & 273.5 \\
\hline Standard error $(\mathrm{m})$ & 0.7 & 0.5 & 18.5 & 15.0 \\
\hline No. of outliers (outliers) & 21 & 44 & - & - \\
\hline
\end{tabular}

covers an area of $90 \times 90$ and $30 \times 30 \mathrm{~m}^{2}$ for $\mathrm{C}$ - and $\mathrm{X}$-bands, respectively. Hence, at higher elevation the accuracy of the SRTM data decreases due to the high undulation.

The main objective of doing the statistical analyses was to answer the following questions:

- Do the C- and X-band SRTM elevation data for the IGS locations adhere to the LE90 error of $16 \mathrm{~m}$ (RMSE $\sim 10 \mathrm{~m})$ SRTM mission goal worldwide? How accurate are they?

- Is there any difference in the quality of coincident $\mathrm{C}$ - and X-band SRTM data?

- How do these results compare with the results obtained from the initial validation of the C-band SRTM data (Rodriguez et al. 2006) given that the RTK GPS method is less accurate than the high-precision static GPS method but provides a denser coverage?

The mean error and the standard deviation for the computed errors of all the stations were found for X- and C-band data. Since the error consisted of random positive and negative values, the quadratic mean/root mean square (RMS) error was computed. The mean absolute error (MAE) was also computed for all the datasets.

\section{Results}

\subsection{Global data}

Statistical analysis for the global data was done with two datasets. The first set contained all the $\mathrm{X}$ - and C-band data, whereas the second set contained data from those stations that had both $\mathrm{X}$ - and C-band data.

Table 2 shows the results of the statistical analysis of the first dataset for both the X- $(30 \mathrm{~m})$ and C-band $(90 \mathrm{~m})$ SRTM data. The X- and C-band data were analysed first without any filtering. The RMS error for both was abnormally high (table 2). The MAE was approximately between 48 and 51 m (table 2). This was due to some stations with abnormally high error. Eliminating these stations as outliers (figure 5a) improved the MAE to $7.8 \mathrm{~m}$ (C-band) and $8.8 \mathrm{~m}$ (X-band) and RMSE to $10.3 \mathrm{~m}$ (C-band) and $11.5 \mathrm{~m}$ (X-band) (table 2).

For the filtered dataset containing all the X(135) and C-band (290) data (table 2), the mean error of the X-and C-band data are 8.2 and $6.9 \mathrm{~m}$ with standard deviation $(1 \sigma), 8.1$ and $7.8 \mathrm{~m}$, respectively. Since the errors for the X-band include both positive and negative values (figure 6), the quadratic mean (RMS) was also calculated; this was $11.5 \mathrm{~m}$. The MAE of X-band data was calculated as $8.8 \mathrm{~m}$ (table 2). The RMS error for C-band was computed to be $10.3 \mathrm{~m}$ and MAE, $7.8 \mathrm{~m}$. The high difference $(\sim 3 \mathrm{~m})$ between the RMS error and MAE for both C- and X-bands signifies a high variance in the individual error in both the samples. The mean error, standard deviation, RMS error and MAE are lower in the C-band data. Although this indicates that the C-band SRTM data are more accurate than the Xband data, a true comparison between the C- and $\mathrm{X}$-band data would come from the analysis of the second dataset containing coincident $\mathrm{X}$ - and C-band data. The SRTM absolute error is plotted against the IGS elevation in figure 7 . The errors are uniformly distributed with respect to elevation as the outlier points have been removed in this dataset.

The results for the second dataset containing only stations that have coincidental $\mathrm{X}$ - and $\mathrm{C}$-band data indicated that the quality of both $\mathrm{C}$ - and $\mathrm{X}$-band was almost the same (table 3 ). The MAE for C-band was $8.8 \mathrm{~m}$ and X-band $8.9 \mathrm{~m}$, the standard deviation $(1 \sigma)$ being $8.3 \mathrm{~m}$ and $8.1 \mathrm{~m}$, respectively. The RMSE of both X- $(11.5 \mathrm{~m})$ and C-band $(11.5 \mathrm{~m})$ datasets are close to the SRTM mission goal of RMSE $\sim 10 \mathrm{~m}$. We next separated the global $\mathrm{X}$ - and $\mathrm{C}$-band dataset into continental subsets to compare the results with the analysis carried out by Rodriguez et al. (2005, 2006).

\subsection{Comparison with initial SRTM assessment}

The SRTM data assessment carried out by Rodriguez et al. (2006) included continent-wise evaluation of the SRTM data by comparing it with 


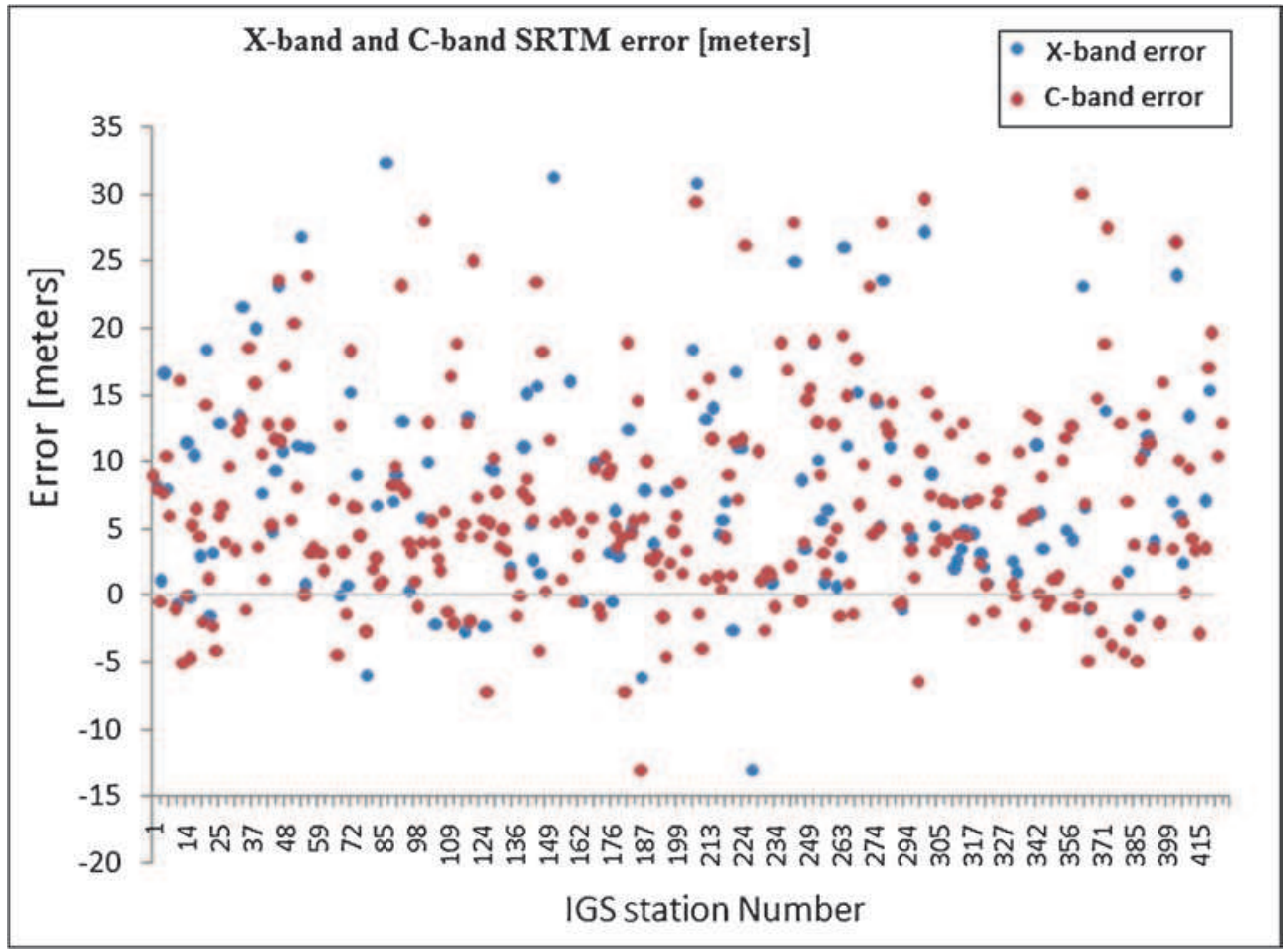

Figure 6. Plot showing the X- and C-band errors for all the IGS stations after removal of outliers in figure 5.

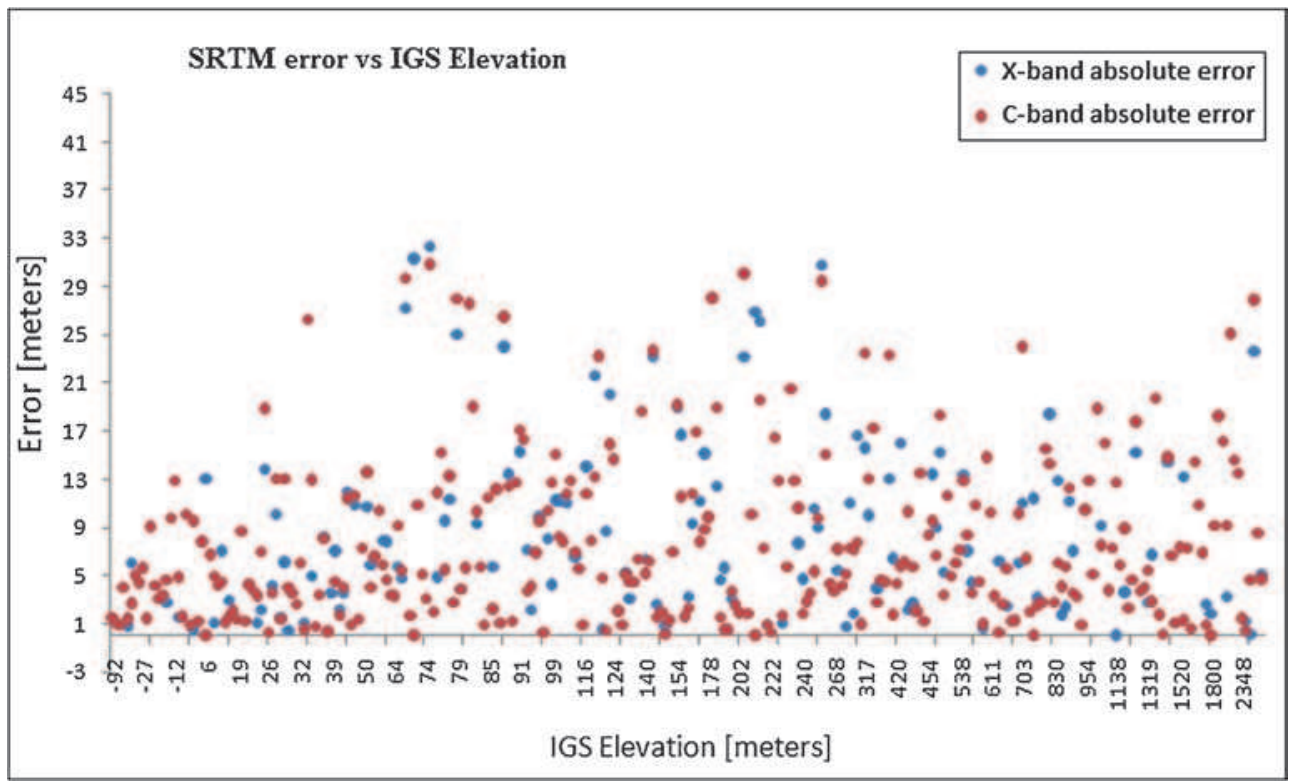

Figure 7. Plot showing X- and C-band absolute errors with increasing elevation of the IGS stations.

GCPs obtained using extensive Kinematic Global Positioning System (KGPS) transects (figure 1b). Australia, Europe and North America have an even spread of GCPs. However, much of Central Asia, Middle East, Indian subcontinent, Northern and Eastern regions of Africa and South America are devoid of any GCPs. Given this, the results of Australia, Europe and North America in the study of Rodriguez et al. $(2005,2006)$ were likely to be more robust than the others. Also, as Europe and Asia were grouped into Eurasia with a much better dataset from Europe than Asia, the results in the study may exhibit a strong bias for Europe. In the Rodriguez et al. (2006) study, the number of RTK GCPs for each continent ranged between 328,000 and 445,000. Although the number of IGS station points used for our study was not comparable to the Rodriguez et al. (2006) GCPs 
Table 3. Results of the statistical analysis of coincidental $X$ - and $C$-band SRTM data.

\begin{tabular}{lccccc}
\hline & \multicolumn{3}{c}{ IGS station with coincident X-and C-band data } \\
\cline { 2 - 3 } Datasets & \multicolumn{2}{c}{ Without outlier } & & \multicolumn{2}{c}{ Including outlier } \\
\cline { 2 - 3 } X-band & C-band & & X-band & C-band \\
\hline Total stations considered & 134 & 131 & & 155 & 155 \\
Mean error (m) & 8.2 & 8.0 & & 34.4 & 34.5 \\
Mean absolute error (m) & 8.9 & 8.8 & & 48.7 & 48.9 \\
RMS error (m) & 11.5 & 11.5 & & 233.3 & 232.7 \\
Standard deviation (m) & 8.1 & 8.3 & & 231.5 & 230.9 \\
Standard error (m) & 0.7 & 0.7 & & 18.6 & 18.6 \\
No. of outliers (outliers) & 21 & 24 & & - & - \\
\hline
\end{tabular}

(figure 1b), the spread of the data was much more even.

In general, the RMS error values were high for all the continental datasets and there was a considerable difference between the RMS error and MAE (table 5). This can be attributed to the high variance of RMS and MAE errors. Since RMS gives a relatively high weightage to large errors and MAE weighs all errors equally, the MAE is comparatively lower. The Absolute Height Error Map for individual C- and X-band data (figure 8) shows the spatial distribution of the absolute errors. The error distribution (figure 8c) did not indicate a normal distribution by the visual inspection of their normal Q-Q plots (figure 9) for both the C- and X-band data. The C-band errors failed the normality test with skewness of 9.18 (standard error $=0.13$ ) and kurtosis of 113.91 (standard error $=0.27$ ). The X-band errors had a skewness of 7.80 (standard error $=0.19$ ) and kurtosis of 71.74 (standard error $=0.39$ ) and also failed the normality test. The Shapiro-Wilk's $(p>0.05)$ (Shapiro and Wilk 1965; Razali and Wah 2011) normality test also failed for both X- and C-band data $(p=0.00)$. The lowest RMSE was observed for Africa, Australia, North America and the Island datasets (tables 4 and 5). The continents of Asia, Europe, Eurasia (combined data from Asia and Europe) and South America showed higher RMSE for both C- and X-band data (tables 4 and 5).

The RMSE obtained from the continent-wise analysis was consolidated and compared with the results obtained from the initial validation of the original SRTM data (Rodriguez et al. 2006) in table 4. The Rodriguez et al. (2006) results were available as LE90 values. As our SRTM errors did not pass the normality test, LE90 results were not applicable. However, in order to compare the results we converted the Rodriguez et al. (2006) LE90 values to RMSE (LE90 = $1.6449 *$ RMSE) (FGDC 1998; Gesch 2007) (table 4).

The computed RMSE for Rodriguez et al. (2006) for all the continents were less than $6.2 \mathrm{~m}$, much below the SRTM mission goal (table 4). In contrast, all our results except the Island datasets had RMSE of over $6.2 \mathrm{~m}$. The RMSE for our Cand X-band SRTM data of Africa, Australia and South America was almost 2 times higher than the Rodriguez et al. (2006) results (table 4). According to the Rodriguez et al. (2006) results, Africa was the most accurate with computed RMSE of $3.4 \mathrm{~m}$, whereas North America had the highest RMSE of $5.5 \mathrm{~m}$. Our results indicated that Island, Australia, North America and Africa datasets had high accuracy for both the $\mathrm{C}$ - and X-band data with RMSE of 5.0, 6.9, 9.0 and $7.9 \mathrm{~m}$ for C-band and 6.1, 7.6, 7.3 and $7.0 \mathrm{~m}$ for X-band respectively (table 4 ). For our study, Europe, Asia and Eurasia were treated as three separate datasets, whereas Rodriguez et al. (2006) analysed a combined Eurasia dataset in which Asia was under-represented. The RMSE of Asia, Europe, Eurasia and South America for both the X- and C-bands were greater than the SRTM mission goal with RMSE of 11.0, 12.4, 11.9 and $11.2 \mathrm{~m}$ for C-band and 14.2, 13.4, 13.8 and $11.5 \mathrm{~m}$ for X-band respectively (table 4).

\subsection{Comparison with other studies}

Several local accuracy assessments have also been carried out in Asia, Australia, Europe and North America and we briefly discuss their results here.

Agrawal et al. (2006) assessment of SRTM data in Asia shows high RMS error for regions of moderately to high undulating terrains of north India. The RMSE for the plain area (Allahabad, India), moderate undulating terrain (Alwar, India) and high undulating terrain (Chamoli, India) are 3.6, 11.4 and $19.6 \mathrm{~m}$, respectively. Another study in Asia (Gorokhovich and Voustianiouk 2006) showed the MAE in Phuket, Thailand to be $7.6 \mathrm{~m}$. A recent study (Rexer and Hirt 2014) that compared SRTM heights with accurate station heights from the Australian National Gravity Database (ANGD) computed an RMSE of $4.4 \mathrm{~m}$ for the C-band study. The study in Poland (Karwel and Ewiak 2008) indicated RMSE of 2.9 and $5.4 \mathrm{~m}$, respectively, for flat and hilly terrain, whereas in north 


\section{Absolute Error Height [meters]}

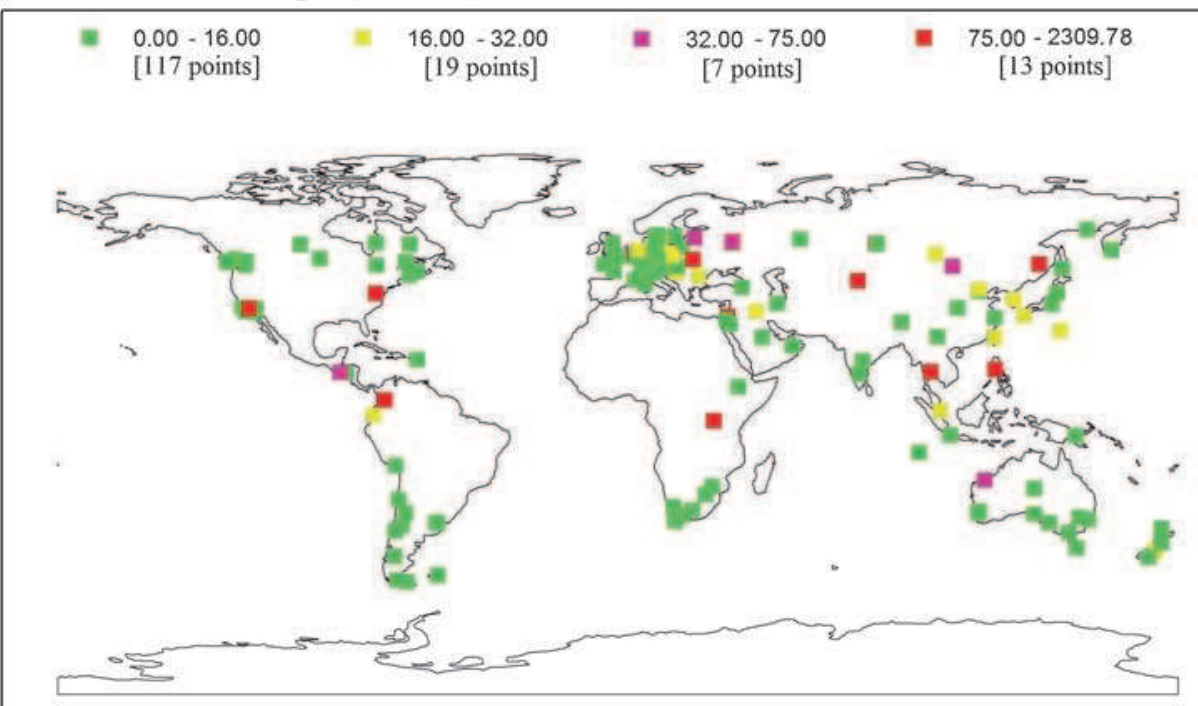

(a) Absolute Error Height Map for X-Band SRTM Data at IGS Stations

\section{Absolute Error Height [meters]}

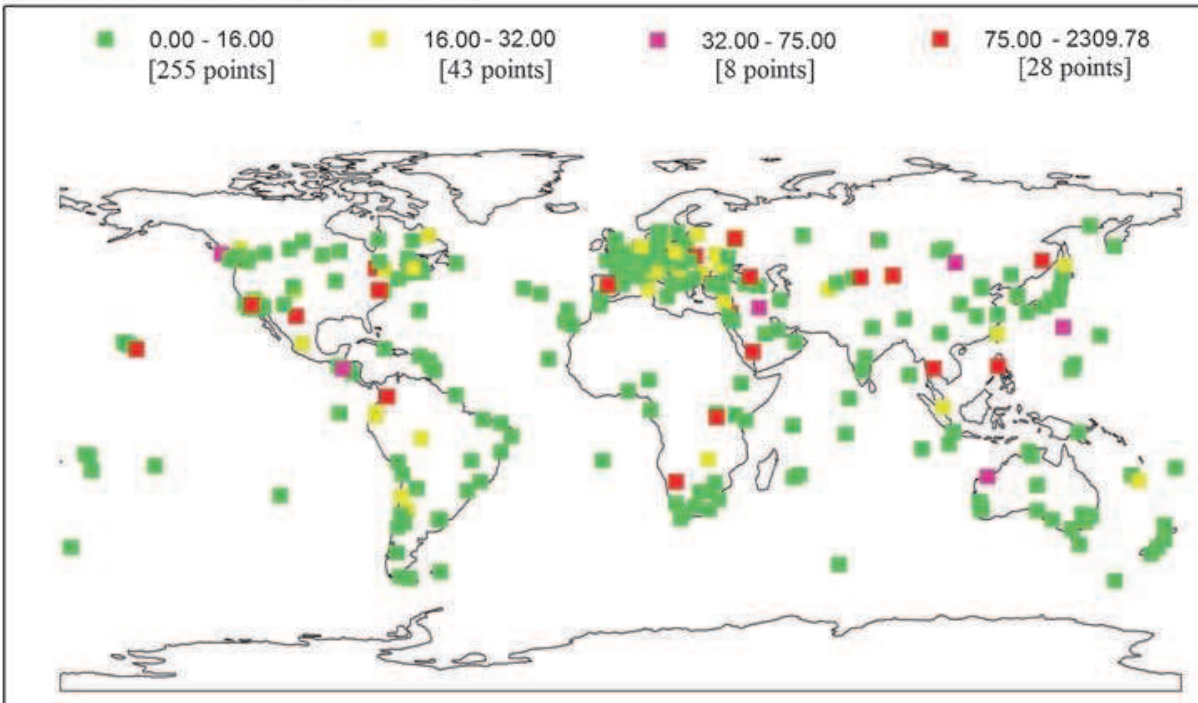

(b) Absolute Error Height Map for C-Band SRTM Data at IGS Stations
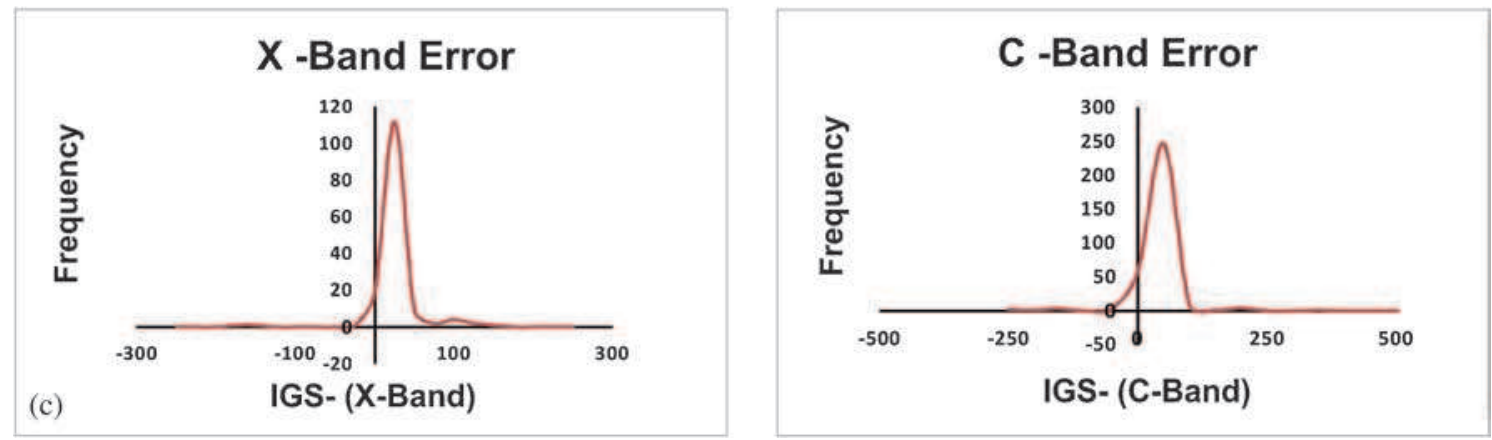

Figure 8. Distribution of (a) X-band and (b) C-band absolute error heights (in meters). Some overlap of data points exist in areas where density of IGS stations is high. The errors exhibit a non-normal distribution (c). 

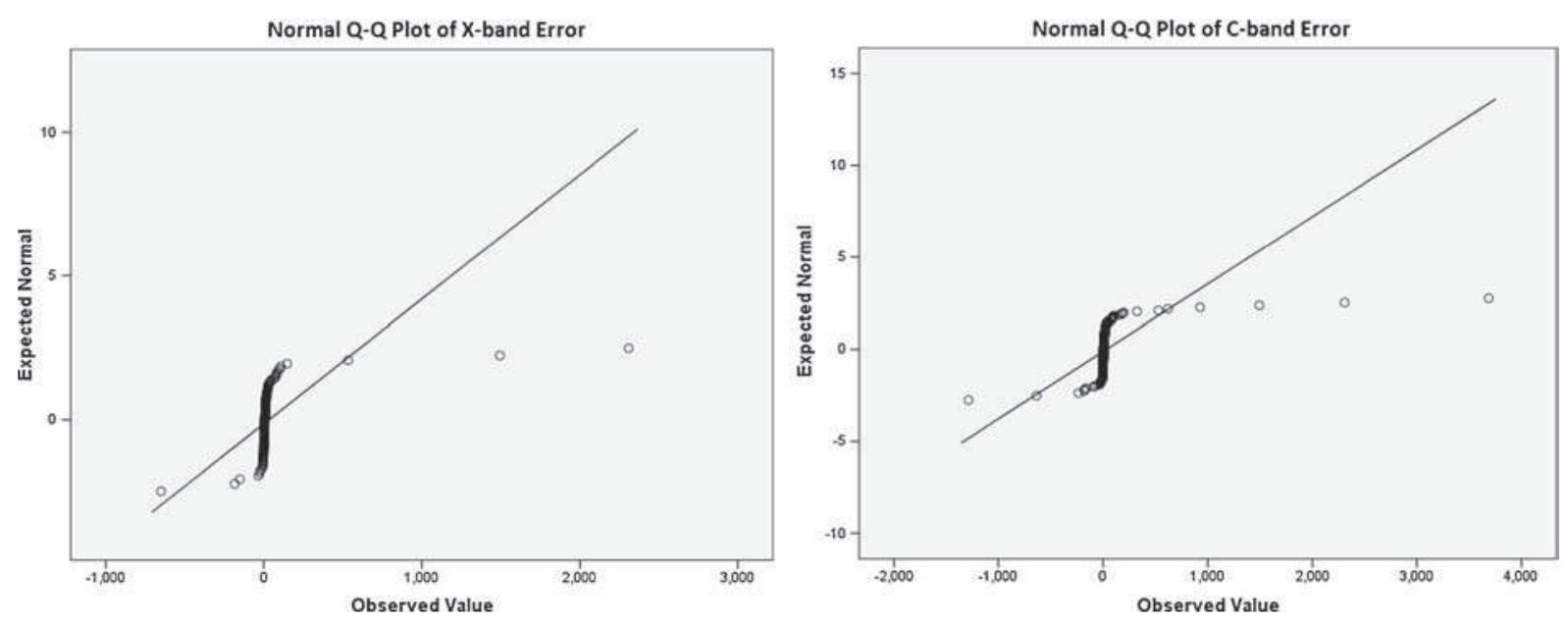

Figure 9. A normal Q-Q plot for both X- and C-band errors showing non-normal distribution.

Table 4. Comparison of RMS error for X- and C-band SRTM data with Rodriguez et al. (2006) results.

\begin{tabular}{lcccc}
\hline Datasets & & & X-band IGS & $\begin{array}{c}\text { C-band IGS } \\
{[\text { RMSE }(\mathrm{m})]}\end{array}$ \\
\hline Global & LE90 $(\mathrm{m})$ & Computed RMSE $(\mathrm{m})$ & 11.5 & 10.3 \\
Africa & 5.6 & 3.4 & 7.0 & 7.9 \\
Australia & 6.0 & 3.7 & 7.6 & 6.9 \\
Asia & - & - & 14.2 & 11.0 \\
Europe & - & - & 13.4 & 12.4 \\
Eurasia & 6.2 & 3.8 & 13.8 & 11.9 \\
Islands & 8.0 & 4.9 & 6.1 & 5.0 \\
North America & 9.0 & 5.5 & 7.3 & 9.0 \\
South America & 6.2 & 3.8 & 11.5 & 11.2 \\
\hline
\end{tabular}

Table 5. Continent-wise results of the statistical analysis of X-and C-band SRTM data.

\begin{tabular}{|c|c|c|c|c|c|c|c|c|c|c|c|c|c|c|c|c|}
\hline \multirow[b]{2}{*}{ Datasets } & \multicolumn{2}{|c|}{ Africa } & \multicolumn{2}{|c|}{ Asia } & \multicolumn{2}{|c|}{ Australia } & \multicolumn{2}{|c|}{ Europe } & \multicolumn{2}{|c|}{ Eurasia } & \multicolumn{2}{|c|}{ Island } & \multicolumn{2}{|c|}{ North America } & \multicolumn{2}{|c|}{ South America } \\
\hline & $\mathrm{X}$ & $\mathrm{C}$ & $\mathrm{X}$ & $\mathrm{C}$ & $\mathrm{X}$ & $\mathrm{C}$ & $\mathrm{X}$ & $\mathrm{C}$ & $\mathrm{X}$ & $\mathrm{C}$ & $\overline{\mathrm{X}}$ & $\mathrm{C}$ & $\mathrm{X}$ & $\mathrm{C}$ & $\mathrm{X}$ & $\mathrm{C}$ \\
\hline Total stations considered & 8 & 23 & 32 & 48 & 16 & 24 & 39 & 88 & 71 & 136 & 2 & 11 & 27 & 72 & 11 & 24 \\
\hline Mean error $(\mathrm{m})$ & 5.7 & 4 & 11.3 & 8 & 5.8 & 3.7 & 10.4 & 9.4 & 10.8 & 8.9 & 6.1 & 2.9 & 3.6 & 6.1 & 8 & 5.2 \\
\hline Mean absolute error $(\mathrm{m})$ & 5.7 & 5.6 & 11.4 & 8.8 & 5.9 & 4.5 & 10.7 & 9.8 & 11 & 9.4 & 6.1 & 3.6 & 5.7 & 7.1 & 9.3 & 7.7 \\
\hline RMS error (m) & 7 & 7.9 & 14.2 & 11 & 7.6 & 6.9 & 13.4 & 12.4 & 13.8 & 11.9 & 6.1 & 5 & 7.3 & 9 & 11.5 & 11.2 \\
\hline Standard deviation (m) & 4.5 & 7 & 8.8 & 6.7 & 5 & 6 & 8.6 & 8.2 & 8.6 & 8 & 0.4 & 4.3 & 6.4 & 6.6 & 8.6 & 10.2 \\
\hline Standard error (m) & 1.6 & 1.5 & 1.4 & 1 & 1.3 & 1.2 & 1.4 & 0.9 & 1 & 0.7 & 0.3 & 1.3 & 1.2 & 0.8 & 2.6 & 2.1 \\
\hline
\end{tabular}

Greece (Mouratidis et al. 2010), the MAE was found to be $6.4 \mathrm{~m}$. An independent study done in the Catskill region (USA) (Gorokhovich and Voustianiouk 2006) computed the MAE to be $4.1 \mathrm{~m}$.

\section{Discussion}

The SRTM data is freely available in two bands, $\mathrm{X}$ and $\mathrm{C}$, at resolutions of 30 and $90 \mathrm{~m}$, and have been used extensively by scientific researchers worldwide in different disciplines. Ever since the release of SRTM data in 2000, many studies have evaluated the quality of this data and all have found it to comply with the SRTM mission goal of $16 \mathrm{~m}$ linear error at $90 \%$ confidence equivalent to RMSE of $\sim 10 \mathrm{~m}$. Global validation of X-band data has not been carried out although some local studies have validated the X-band data (e.g., Turkey (Sefercik and Alkan 2009) and Poland (Kolecka and Kozak 
2013)) and observed that the accuracy of the Xband data was in the same range as C-band SRTM and the latter was marginally more accurate. However, these studies did not use GPS data to test the accuracy of the X-band SRTM data. The initial, and most comprehensive, evaluation of SRTM C-band data was done by Rodriguez et al. (2005) by taking kinematic GPS transects across all the continents (figure 1b). The results obtained were averaged out for the different continents. Other studies (Falorni et al. 2005; Agrawal et al. 2006; Gorokhovich and Voustianiouk 2006; Karwel and Ewiak 2008; Mouratidis et al. 2010) using localized datasets have also validated C-band SRTM data. Majority of the studies used GPS data to assess the C-band SRTM accuracy. However, the type of GPS receivers used and the methodology were different. This study focused on evaluating both C- and X-band SRTM data in a different way by using the global IGS station network where the data collection is carried out using dual-frequency, high-precision static receivers with post-processing. The IGS stations provide the most accurate GCPs possible at present and are scattered worldwide. Hence, an important, and independent, global analysis of the SRTM elevation values has been attempted with this dataset to complement the comprehensive SRTM global accuracy analysis carried out by Rodriguez et al. (2005, 2006).

Our analysis consisted of first assessing the SRTM data at the IGS locations as a single global set. An important observation was the presence of high-error outliers for both $\mathrm{X}$ - and C-band datasets. The RMSE of the outlier-filtered data is in the range of $10.0-11.5 \mathrm{~m}$ for both the bands with C-band showing a higher accuracy compared to $\mathrm{X}$-band (table 2). However, the results of the coincident $\mathrm{X}$ - and $\mathrm{C}$-band data indicated that the accuracy of both the $\mathrm{X}$ - and C-band data were the same (RMSE of $11.5 \mathrm{~m}$; table 3 ) and did not satisfy the SRTM goal. With the outlier data included ( $100 \%$ data), the RMSE increased $\sim 20$ times for both bands of SRTM data. This suggests that the SRTM mission goal of an absolute vertical accuracy within $\pm 16 \mathrm{~m}$ (LE90)/RMSE $\sim 10 \mathrm{~m}$ is not satisfied upfront if we accept that the elevation of the IGS stations are closest to the truth as they represent GCPs having an accuracy of $6 \mathrm{~mm}$ (Dow et al. 2009). Identification and filtering the outliers of the IGS station dataset is required to bring down the error close to the limits of SRTM mission goal.

In the second part of our study, we grouped the data into continents and analysed the results by comparing it with the Rodriguez et al. (2005, 2006) results (table 4) after removing the outliers. Our RMSE for all the continents were higher than the computed RMSE of the Rodriguez et al. (2005) study. The results of Africa, Australia, Islands and North America for both X- and C-bands complied with the SRTM mission goal. The results clearly show that the SRTM data exhibits regional variations in accuracy. Thus, the error obtained using a few RTK GPS transects may not be valid for the entire continent. To assess the error at the continent level, we need many more GCPs from all parts of the continent. Also, the Rodriguez et al. (2005) kinematic GPS transects for Eurasia contain much more data from Europe than Asia, and so merging Europe and Asia may also be problematic. We combined our Asia and Europe datasets as Eurasia to compare with the Rodriguez et al. (2005). Our RMSE of $11.9 \mathrm{~m}$ for the C-band data was higher than the computed Rodriguez et al. (2005) RMSE of $3.8 \mathrm{~m}$ (table 4$)$.

\section{Conclusions}

- The C- and X-band SRTM elevation data for the IGS locations do not adhere to the SRTM mission goal of $16 \mathrm{~m}$ vertical error (RMSE $\sim 10 \mathrm{~m}$ ) for outlier-filtered worldwide data. The mean and standard error of the difference between IGS and SRTM elevations for the worldwide dataset was computed to be $8.2 \pm 0.7 \mathrm{~m}$ and $6.9 \pm 0.5 \mathrm{~m}$ for X- and C-band data, respectively, which indicates the presence of a positive bias for both bands of SRTM data.

- The analysis of coincidental X-and C-band data indicates that the quality of both the $\mathrm{X}$ - and C-band data is same as the RMSE for both is $11.5 \mathrm{~m}$.

- Africa, Australia and North America have a vertical accuracy within the SRTM mission goal of $\sim 10 \mathrm{~m}$ RMSE. Asia and Europe reported the highest RMSE for the X- and C-band data, respectively. X-band data was more accurate than C-band data for Africa and North America.

- The results obtained from the initial validation of the C-band SRTM data using RTK GPS stations (Rodriguez et al. 2006) do not compare well with the results of this study using IGS stations as RMSE of all the continents are much higher than the computed RMSE of the Rodriguez et al. (2006) study.

\section{Acknowledgements}

This is an IITBESCDL/001/2014 publication. The work was funded by the Ministry of Earth Sciences India, Grant No. MoES/16/01/09-RDEAS 
and Department of Science and Technology India, Grant No. SR/S4/ES-415/2009 to Malay. VS acknowledges IITB for the Teaching Assistantship in the Department of Earth Sciences. Critical reviews by two anonymous reviewers and comments of the JESS handling editor helped to significantly improve the quality of this paper. We are grateful to the editorial staff of JESS for painstakingly putting this paper together. We benefited from discussions with Sridevi Jade, D Ramakrishnan and Rishikesh Bharti.

\section{References}

Agrawal R, Mahtab A, Jayaprasad P, Pathan S K and Ajai 2006 Validating SRTM DEM with differential GPS Measurements - A case study with different terrains; Proceedings of the Symposium of International Society for Photogrammetry and Remote Sensing, Goa, India, September 25-30.

Altamimi Z, Collilieux X, Legrand J, Garayt B and Boucher C 2007 ITRF2005: A new release of the International Terrestrial Reference Frame based on time series of station positions and Earth Orientation Parameters; J. Geophys. Res.: Solid Earth 112(9). doi: 10.1029/2007JB004949.

Bamler R 1999 The SRTM mission: A world-wide $30 \mathrm{~m}$ resolution DEM from SAR interferometry in 11 days; In: Photogrammetric week (eds) Fritsch R and Spiller R, pp. $145-154$.

Blumberg D, Bach D, Weissel J, Gorokhovich Y, Small C and Balk D 2005 The 2004 Sumatra Tsunami event: Contribution of SRTM data to the analysis of devastation; The Shuttle Radar Topography Mission - Data Validation and Applications Workshop, June 14-16, Reston, Virginia.

Ciampalini R, Martin M P, Saby N P A, Richer De Forges A C, Arrouays D, Nehlig P and Martelet G 2013 Modelling soil particle-size distribution in the region centre (France); Proceedings of 1st Global Soil Map Conference: Basis of the Global Spatial Soil Information System, Orleans, France, October 7-9, Code 102494.

Dow J M, Neilan R E and Rizos C 2009 The International GNSS service in a changing landscape of global navigation satellite; J. Geodesy 83 191-198.

El-Rabbany A 2002 Introduction to GPS, The Global Positioning System; Artech House, Mobile Communication Series.

Falorni G, Teles V, Vivoni E R, Bras R L and Amaratunga K S 2005 Analysis and characterization of the vertical accuracy of digital elevation models from the Shuttle Radar Topography Mission; J. Geophys. Res. 110 Article No. F02005.

Farr T G and Kobrick M 2000 Shuttle radar topography mission produces a wealth of data; T. Am. Geophys. Union $81583-585$.

Farr T G, Rosen P A, Caro E, Crippen R, Duren R, Hensley S, Kobrick M, Paller M, Rodriguez E, Roth L, Seal D, Shaffer S, Shimada J, Umland J, Werner M, Oskin M, Burbank M and Alsdorf D 2007 The Shuttle Radar Topography Mission; Rev. Geophys. 45 RG2004, doi: 10.1029/2005RG000183.

FGDC 1998 Geospatial Positioning Accuracy Standards. Part 3: National Standard for Spatial Data Accuracy; Federal Geographic Data Committee, USA. http://www. fgdc.gov/standards/standards_publications/.
Gesch D B 2007 The National Elevation Dataset; In: Digital elevation model technologies and applications; The DEM users manual (ed.) Maune D, 2nd edn, Bethesda, Maryland, American Society for Photogrammetry and Remote Sensing, pp. 99-118.

Gorokhovich Y and Voustianiouk A 2006 Accuracy assessment of the processed SRTM-based elevation data by CGIAR using field data from USA and Thailand and its relation to the terrain characteristics; Rem. Sens. Environ. 104 409-415.

Grohman G, Kroenung G and Strebeck J 2006 Filling SRTM voids: The delta surface fill method; Photogramm. Eng. Rem. Sens. 72 213-216.

Hanssen R F 2001 Radar Interferometry: Data interpretation and analysis; Springer, New York.

Hoffmann J and Walter D 2006 How complementary are SRTM X- and C-band digital elevation models? Photogramm. Eng. Rem. Sens. 72 261-268.

Jaber WA, Floricioiu D, Rott H and Eineder M 2013 Surface elevation changes of glaciers derived from SRTM and TanDEM-X DEM differences; Proceedings of the 33rd IEEE International Geoscience and Remote Sensing Symposium (IGARSS) 2013, Melbourne, VIC, Australia, July 21-26, Article No. 6723173, pp. 1893-1896.

JPL Shuttle Radar Topography Mission 2009 Technical Fact Sheet; http://www2.jpl.nasa.gov/srtm/index.html.

Karwel A K and Ewiak I 2008 Estimation of the accuracy of the SRTM terrain model on the area of Poland; International Archives of the Photogrammetry; Rem. S. Spatial Inform. Sci. 37 B7.

Kellndorfer J, Walker W, Pierce L, Dobson C, Fites J A and Hunsaker C 2004 Vegetation height estimation from shuttle radar topography mission and national elevation datasets; Rem. Sens. Environ. 93 339-358.

Kolecka N and Kozak J 2013 Assessment of the accuracy of SRTM C- and X-band high mountain elevation data: A case study of the Polish Tatra mountains; Pure Appl. Geophys., doi: 10.1007/s00024-013-0695-5.

Lemoine F G, Kenyon S C, Factor J K, Trimmer R G, Pavlis N K, Chinn D S, Cox C M, Klosko S M, Luthcke S B, Torrence M H, Wang Y M, Williamson R G, Pavlis E C, Rapp R H and Olson T R 1998 The development of the joint NASA GSFC and National Imagery and Mapping Agency (NIMA) Geopotential Model EGM96; Technical Paper NASA/TP-1998-206861.

Mahammad S and Ramakrishnan R 2010 GeoTiff - A standard image file format for GIS applications; Space Application Centre, ISRO, Ahmedabad.

Miliaresis G C H and Paraschou C V E 2005 Vertical accuracy of the SRTM DTED level 1 of Crete; Int. J. Appl. Earth Observ. Geoinform. 7 49-59.

Mouratidis A, Briole P and Katsambalos K 2010 SRTM 3 arc DEM (versions 1, 2, 3, 4) validation by means of extensive kinematic GPS measurements: A case study from North Greece; Int. J. Rem. Sens. 31 6205-6222.

Rabus B, Eineder M, Roth Am and Bamler R 2004 The shuttle radar topography mission - a new class of digital elevation models acquired by space borne radar; J. Photogramm. Rem. Sens. 57 241-262.

Rapp R H 1997 Use of potential coefficient models for geoid undulation determinations using a spherical harmonic representation of the height anomaly/geoid undulation difference; J. Geodesy 71 282-289.

Razali N M and Wah Y B 2011 Power comparisons of Shapiro-Wilk, Kolmogorov-Smirnov, Lilliefors and Anderson-Darling test; J. Stat. Model. Analytics 2 21-33.

Rexer M and Hirt C 2014 Comparison of free high resolution digital elevation data sets (ASTER GDEM2, SRTM 
v2.1/v4.1) and validation against accurate heights from the Australian National Gravity Database; Aust. J. Earth Sci. $61213-226$.

Rodriguez E, Morris C S and Belz J E 2006 A global assessment of the SRTM performance; Photogramm. Eng. Rem. Sens. 72 249-260.

Rodriguez E, Morris C S, Belz J E, Chapin E C, Martin J M and Daffer W 2005 An assessment of the SRTM topographic products; Technical Report JPLD-31639, Pasadena, California: Jet Propulsion Laboratory, 2005, $143 p$.

Sefercik U G and Alkan M 2009 Advanced analysis of differences between $\mathrm{C}$ and $\mathrm{X}$ bands using SRTM data for mountainous topography; J. Indian Soc. Rem. Sens. 37 $335-349$.
Shapiro S S and Wilk M B 1965 An analysis of variance test for normality (complete samples); Biometrika 52 591-611.

Sleszynski P 2013 A geomorphometric analysis of Poland based on the SRTM-3 data; Geographia Polonica 85 45-59.

Toutin T 2002 Impact of terrain slope and aspect on radargrammetric DEM accuracy ISPRS; J. Photogramm. Rem. Sens. 57 228-240.

USGS 2005 Shuttle radar topography mission; http://srtm. usgs.gov.

Van Zyl J J 2001 The shuttle radar topography mission (SRTM): A breakthrough in remote sensing of topography; Acta Astronautica 48 559-565.

Werner M 2001 Shuttle radar topography mission (SRTM), mission overview; J. Telecommun. (Frequenz) $\mathbf{5 5}$ 75-79.

MS received 2 September 2014; revised 4 March 2015; accepted 14 April 2015 